\title{
Repeatability and reproducibility of axial length, anterior chamber depth and crystalline lens thickness measurements using the Nidek US-500 Echoscan
}

\author{
Author: \\ Khathutshelo P. Mashige ${ }^{1}$ \\ Affiliation: \\ ${ }^{1}$ Discipline of Optometry, \\ School of Health Sciences, \\ University of KwaZulu-Natal, \\ South Africa \\ Correspondence to: \\ Khathutshelo Mashige \\ Email: \\ mashigek@ukzn.ac.za \\ Postal address: \\ Private Bag X54001, Durban \\ 4000, South Africa

\section{Dates:} \\ Received: 03 Sept. 2014 \\ Accepted: 14 Jan. 2015 \\ Published: 31 July 2015 \\ How to cite this article: \\ Mashige KP. Repeatability \\ and reproducibility of axial \\ length, anterior chamber \\ depth and crystalline lens \\ thickness measurements \\ using the Nidek US-500 \\ Echoscan. Afr Vision Eye \\ Health. 2015;74(1), Art. \\ \#16, 6 pages. http://dx.doi. \\ org/10.4102/aveh.v74i1.16

\section{Copyright:} \\ (C) 2015. The Author(s). \\ Licensee: AOSIS \\ OpenJournals. This work is \\ licensed under the Creative \\ Commons Attribution \\ License.
}

\section{Read online:}

Aim: The reliability of an instrument used to collect data for clinical and research purposes is greatly important, especially when it is used to determine changes in measured ocular parameters over time. The purpose of this study was to determine the intra-session repeatability and inter-session reproducibility of axial length (AL), anterior chamber depth (ACD) and crystalline lens thickness (LT) measurements using the Nidek US-500 Echoscan.

Method: Fifty successive automatic measurements of the above parameters were taken on the right eyes only of 12 healthy subjects aged 23-44 years old, followed by similar repeated measures after 1 week. Sample standard deviations (s.d.), precision (P) and coefficient of repeatability (COR) were calculated to determine intra-session repeatability. Coefficient of reproducibility (CRP), Bland and Altman plots, concordance correlation coefficients (CCC) and paired $t$-tests that compared measurements obtained in the first and second sessions, were used to determine inter-session reproducibility.

Results: Both the intra-session repeatability and inter-session reproducibility were within acceptable limits for the three variables assessed.

Conclusion: The study showed that the Nidek US-500 Echoscan provides accurate, repeatable and reproducible measurements of $\mathrm{AL}, \mathrm{ACD}$ and $\mathrm{LT}$ in healthy eyes. This finding will be of interest to optometrists and ophthalmologists who measure these parameters when diagnosing, managing and investigating conditions such as primary angle-closure glaucoma and keratoconus.

\section{Introduction}

Accurate measurements of ocular parameters such as axial length (AL), anterior chamber depth (ACD) and crystalline lens thickness (LT) are important for biometric studies of refractive error development and progression, crystalline lens growth, presbyopia and cataract surgery. ${ }^{1}$ Most formulas that are used to calculate the power of intraocular lenses (IOL) rely on an accurate measurement of the distance between the IOL and the retina, which can be calculated from the difference between total AL and ACD. ${ }^{1}$ In addition, accurate assessment of ACD is important in the diagnosis and management of acute or chronic primary angle-closure glaucoma (PACG), ${ }^{2}$ keratoconus and lenticonus., ${ }^{3,4}$ Furthermore, biometric studies of myopia and PACG rely on accurate measurements of crystalline LT. ${ }^{5,6}$ For example, biometric studies have shown that acute primary angle-closure glaucoma (APACG) eyes have shorter ALs ${ }^{7}$ and shallower anterior chambers. ${ }^{8}$ Mei et al. ${ }^{9}$ have shown that subjects with PACG have thicker lenses and more anteriorly located lenses than normal controls. The study further showed that symptomatic PACG-affected patients have the shallowest ACD and thicker LT, and the authors concluded that smaller ocular biometric measurements may be clinical indicators for APACG.

Various types of instruments are available for measuring AL, ACD and LT. These include ultrasonic biometers, the IOLMaster, Lenstar, Pentacam and optical coherence tomography. ${ }^{10}$ Recently, a device for the simultaneous automated contact evaluation of AL, ACD and LT has been developed, namely, the Nidek US-500 Echoscan:

The ultrasonic pulse from the instrument travels inside the eye when the probe is placed on the eyeball. A portion of the pulses is reflected from the boundary of the cornea, anterior chamber, lens, vitreous body and retina, and their echoes are received at the same probe. The received echoes are converted to electronic acoustic echoes and indicated on the LCD as an amplitude. The time difference of each echo is measured and the size of each area tissue (axial length, anterior chamber depth, crystalline lens thickness and vitreous body length) is calculated according to the time difference known inherent sonic velocity through each kind of tissue..$^{11}$ (n.p.) 
The device is portable and can therefore be used on domiciliary visits as well as outside the limits of a consulting room. However, its measurements may be influenced by ocular accommodation ${ }^{12,13}$ and the method requires the instillation of topical anaesthesia. The process usually involves corneal contact and as such may be inconvenient to some patients and not suitable for children. In addition, precise positioning of the probe is difficult because there is no distinct landmark that can be used to align the probe with the cornea. ${ }^{11}$

Measurements made with this type of device therefore need to be assessed for intra-session repeatability and inter-session reproducibility as these are of clinical and research importance. Intra-session repeatability is the agreement between measurements taken by a single examiner during the same session on the same subject and under the same measurement conditions. ${ }^{14}$ Inter-session reproducibility refers to the extent of agreement between measurements taken on the same subjects during different sessions. ${ }^{15}$ No previous study could be found in the literature that assessed repeatability and reproducibility of the Nidek US-500 Echoscan. The aim of this study, therefore, was to determine the intra-session repeatability and inter-session reproducibility of AL, ACD and LT measurements obtained with this instrument in subjects with healthy eyes.

\section{Methods}

An experimental design was adopted in this study. A withinsubjects design was used for repeatability measures, whilst a between-subjects design was used for reproducibility. All participants were chosen by convenience sampling and met a minimum uncompensated visual acuity (VA) criterion of $6 / 6$ or better monocularly. Subjects with any form of ocular pathology, history of ocular trauma or contact lens wear, and previous ocular surgery were excluded from the study. All subjects included in the study reported having good health. These issues were determined by performing a complete ocular examination, which included refraction, direct ophthalmoscopy, slit lamp biomicroscopy and administration of a brief questionnaire. Twelve subjects (6 women and 6 men) aged 23-44 years (mean $27.4 \pm 4.1$ years) participated in the study. The study followed the tenets of the Declaration of Helsinki and was approved by the University of KwaZuluNatal's Biomedical Research and Ethics Committee. Written informed consent was obtained from all participants after the nature of the study had been explained to them. Participants were assured that their data would be presented anonymously to protect their identity.

Each subject was comfortably seated and asked to keep both eyes open and to fixate on a fixation light at a distance of $6 \mathrm{~m}$. The Nidek US-500 was calibrated prior to measurement of data. The instrument's probe was placed perpendicular to the cornea at $1.5 \mathrm{~mm}$ temporally from the reflex of the fixation light. Measurements for each session were taken following instillation of one drop of $0.4 \%$ oxybuprocaine hydrochloride. A wait of 20 seconds was allowed for the anaesthetic to take effect. ${ }^{16}$ Little conjunctival irritation and hyperaemia occurs with $0.4 \%$ oxybuprocaine hydrochloride. ${ }^{16}$ The probe was sterilised with hydrogen peroxide before use and between measurements on each subject. For intrasession repeatability, $50 \mathrm{AL}, \mathrm{ACD}$ and $\mathrm{LT}$ consecutive automatic sets of measurements were obtained for the right eye of each subject in approximately 15-20 minutes. All measurements were made by the same operator with the eyes of the subjects in their natural, undilated state. The measurements were taken in a room with constant illumination as measured with a light meter. For assessment of inter-session reproducibility, the measurements were made on the same eyes of the 12 subjects after 1 week. The measurement protocol remained the same and the time of day for each measurement session was approximately the same for each session.

\section{Statistical analysis}

Statistica and Medcalc software packages were used to calculate intra-session repeatability and inter-session reproducibility. Intra-session repeatability of each of the variables was evaluated by calculating the standard deviation (s.d.), precision (P) and coefficient of repeatability (COR). ${ }^{17}$ Inter-session reproducibility was assessed by comparing multiple measurements, taken after 1 week. The coefficient of reproducibility (CRP) was calculated with the Bland-Altman plots ${ }^{18,19}$ using the mean variable measurement and the calculated 95\% limits of agreement (95\% LoA) (mean difference \pm 1.96 s.d.). ${ }^{17}$ Also, intersession reproducibility was evaluated by calculating the concordance correlation coefficients (CCC), and paired $t$-tests were conducted on each initial session $\mathrm{v}$. second session of measurements.

\section{Results}

Table 1 shows the mean AL, ACD and LT of each subject obtained during the first and second measurement sessions. Table 2 shows the mean differences and 95\% upper limit (UL) and lower limit (LL) from the Bland-Altman plots for the data collected during sessions one and two, and Table 3 shows the CCC and their 95\% confidence intervals (CI).

Precision ranged from $0.06 \mathrm{~mm}-0.29 \mathrm{~mm}$ for AL, $0.06 \mathrm{~mm}-$ $0.19 \mathrm{~mm}$ for ACD, and $0.05 \mathrm{~mm}-0.18 \mathrm{~mm}$ for LT. COR (no units) ranged from $0.16-0.68$ for $A L, 1.30-3.07$ for $A C D$, and 0.93-2.36 for LT.

Figures 1-3 show single Bland-Altman plots of AL, ACD and LT respectively for Subject 3. Each plot indicates the mean of the differences between the 50 measurements with a long and slightly thicker straight line as well as the $95 \%$ LoA (mean difference \pm 1.96 s.d.), indicated using horizontal dotted lines. Thin horizontal lines are used to indicate 95\% CIs around the mean difference and the upper and lower limits (or LoA). For brevity, only three Bland-Altman 
TABLE 1: Descriptive statistics for axial length, anterior chamber depth and lens thickness for each subject, performed in the first and second sessions.

\begin{tabular}{|c|c|c|c|c|c|c|c|}
\hline \multirow[t]{2}{*}{ Subject } & \multirow[t]{2}{*}{ Session } & \multicolumn{2}{|c|}{ Axial length } & \multicolumn{2}{|c|}{ Anterior chamber depth } & \multicolumn{2}{|c|}{ Lens thickness } \\
\hline & & Mean & $\begin{array}{c}95 \% \text { confidence } \\
\text { interval }\end{array}$ & Mean & $\begin{array}{c}95 \% \text { confidence } \\
\text { interval }\end{array}$ & Mean & $\begin{array}{l}95 \% \text { confidence } \\
\text { interval }\end{array}$ \\
\hline \multirow[t]{2}{*}{ S1 } & 1 & $22.88 \pm 0.05$ & $22.87-22.90$ & $3.17 \pm 0.07$ & $3.14-3.19$ & $3.56 \pm 0.08$ & $3.54-3.59$ \\
\hline & 2 & $22.92 \pm 0.07$ & $22.89-22.94$ & $3.18 \pm 0.07$ & $3.16-3.20$ & $3.53 \pm 0.03$ & $3.52-3.54$ \\
\hline \multirow[t]{2}{*}{ S2 } & 1 & $23.06 \pm 0.04$ & $23.04-23.07$ & $3.23 \pm 0.04$ & $3.22-3.24$ & $3.51 \pm 0.03$ & $3.50-3.52$ \\
\hline & 2 & $23.18 \pm 0.03$ & $23.12-23.14$ & $3.22 \pm 0.03$ & $3.21-3.23$ & $3.51 \pm 0.02$ & $3.50-3.52$ \\
\hline \multirow[t]{2}{*}{ S3 } & 1 & $22.81 \pm 0.09$ & $22.79-22.84$ & $3.16 \pm 0.09$ & $3.13-3.18$ & $3.58 \pm 0.03$ & $3.57-3.59$ \\
\hline & 2 & $22.84 \pm 0.03$ & $22.82-22.85$ & $3.21 \pm 0.04$ & $3.20-3.23$ & $3.57 \pm 0.02$ & $3.57-3.58$ \\
\hline \multirow[t]{2}{*}{ S4 } & 1 & $23.61 \pm 0.05$ & $23.57-23.65$ & $3.16 \pm 0.04$ & $3.15-3.18$ & $3.41 \pm 0.04$ & $3.40-3.43$ \\
\hline & 2 & $23.56 \pm 0.04$ & $23.54-23.57$ & $3.17 \pm 0.04$ & $3.16-3.19$ & $3.37 \pm 0.06$ & $3.35-3.38$ \\
\hline \multirow[t]{2}{*}{ S5 } & 1 & $22.16 \pm 0.03$ & $22.14-22.19$ & $3.14 \pm 0.09$ & $3.14-3.16$ & $3.54 \pm 0.07$ & $3.52-3.57$ \\
\hline & 2 & $23.14 \pm 0.02$ & $23.12-23.14$ & $3.20 \pm 0.04$ & $3.18-3.22$ & $3.56 \pm 0.01$ & $3.53-3.57$ \\
\hline \multirow[t]{2}{*}{ S6 } & 1 & $22.84 \pm 0.06$ & $22.78-22.86$ & $3.19 \pm 0.05$ & $3.16-3.20$ & $3.54 \pm 0.04$ & $3.49-3.56$ \\
\hline & 2 & $22.83 \pm 0.05$ & $22.81-22.85$ & $3.16 \pm 0.04$ & $3.15-3.18$ & $3.57 \pm 0.02$ & $3.57-3.59$ \\
\hline \multirow[t]{2}{*}{ S7 } & 1 & $23.66 \pm 0.01$ & $23.64-23.71$ & $3.12 \pm 0.06$ & $3.10-3.15$ & $3.55 \pm 0.05$ & $3.53-3.57$ \\
\hline & 2 & $23.66 \pm 0.05$ & $22.62-22.68$ & $3.19 \pm 0.03$ & $3.17-3.21$ & $3.55 \pm 0.04$ & $3.51-3.56$ \\
\hline \multirow[t]{2}{*}{ S8 } & 1 & $23.04 \pm 0.02$ & $23.01-23.06$ & $3.21 \pm 0.03$ & $3.19-3.23$ & $3.47 \pm 0.01$ & $3.45-3.48$ \\
\hline & 2 & $22.54 \pm 0.03$ & $22.52-23.56$ & $3.13 \pm 0.05$ & $3.12-3.15$ & $3.40 \pm 0.04$ & $3.38-3.41$ \\
\hline \multirow[t]{2}{*}{ S9 } & 1 & $23.44 \pm 0.03$ & $23.42-23.46$ & $3.13 \pm 0.06$ & $3.11-3.16$ & $3.46 \pm 0.04$ & $3.44-3.52$ \\
\hline & 2 & $22.88 \pm 0.06$ & $22.86-22.90$ & $3.14 \pm 0.05$ & $3.12-3.16$ & $3.50 \pm 0.05$ & $3.52-5.54$ \\
\hline \multirow[t]{2}{*}{ S10 } & 1 & $23.08 \pm 0.03$ & $23.04-23.11$ & $3.21 \pm 0.05$ & $3.18-3.22$ & $3.44 \pm 0.06$ & $3.40-3.45$ \\
\hline & 2 & $23.14 \pm 0.05$ & $23.12-23.15$ & $3.20 \pm 0.04$ & $3.18-3.22$ & $3.48 \pm 0.03$ & $3.47-3.50$ \\
\hline \multirow[t]{2}{*}{ S11 } & 1 & $22.18 \pm 0.06$ & $22.16-22.20$ & $3.13 \pm 0.07$ & $3.11-3.15$ & $3.54 \pm 0.04$ & $3.52-3.56$ \\
\hline & 2 & $23.81 \pm 0.03$ & $23.78-23.82$ & $3.20 \pm 0.04$ & $3.18-3.22$ & $3.54 \pm 0.05$ & $3.52-3.56$ \\
\hline \multirow[t]{2}{*}{ S12 } & 1 & $22.68 \pm 0.03$ & $22.65-22.70$ & $3.14 \pm 0.07$ & $3.11-3.17$ & $3.39 \pm 0.04$ & $3.37-3.40$ \\
\hline & 2 & $22.94 \pm 0.04$ & $22.90-22.96$ & $3.19 \pm 0.03$ & $3.17-3.20$ & $3.33 \pm 0.05$ & $3.32-3.36$ \\
\hline
\end{tabular}

$\mathrm{S} 1-\mathrm{S} 12$ = subject numbers. All values are in $\mathrm{mm}$.

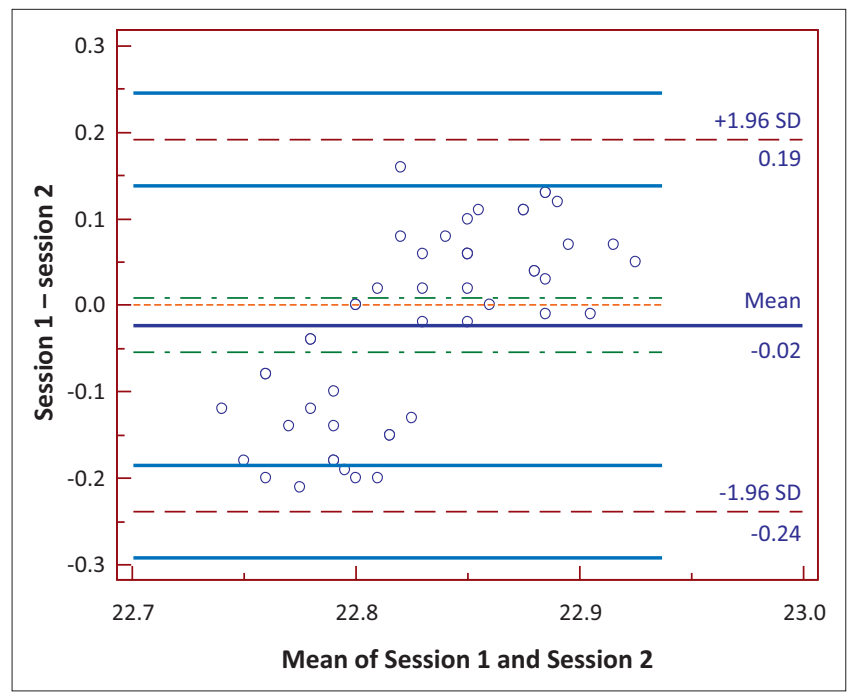

Note: Fifty measurements of axial length were obtained per session. The $x$-axis indicates the means across the measures or sessions and the $y$-axis indicates the differences between the two measures. The mean difference $(-0.02 \mathrm{~mm})$ is indicated by the long and thicker horizontal solid line and is labelled Mean. The $95 \%$ limits of agreement (mean difference \pm 1.96 s.d.) are indicated by the horizontal long dotted lines. Thinner horizontal solid lines indicate $95 \%$ regions of uncertainty (95\% confidence intervals) about the mean difference, and upper and lower limits of agreement. In other words, the mean difference lies somewhere within its $95 \% \mathrm{Cl}$ and similarly for the upper and lower limits of agreement. The smaller the $\mathrm{Cl}$, the more certain is the estimate (of the mean difference or limits of agreement) concerned.

FIGURE 1: A Bland-Altman plot for Subject 3 showing inter-session reproducibility in axial length measurements (session 1 - session 2) against their combined average, with the $95 \%$ limit of agreement depicted.

plots for randomly selected, Subject 3, are shown (plots for other subjects were essentially similar to those shown in Figures 1, 2 and 3), and the relevant values for mean differences, LoA and CIs from the graphs for other subjects are shown in Table 2.

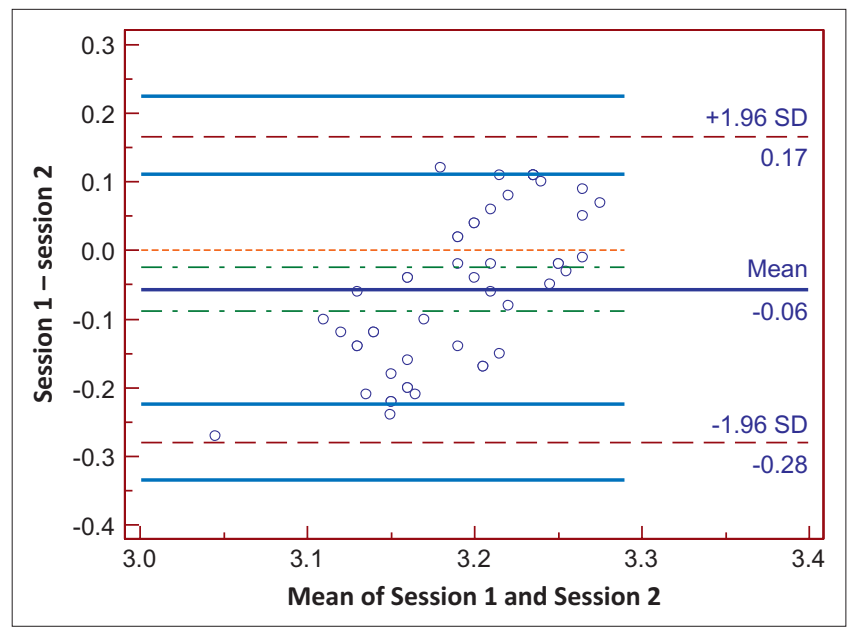

FIGURE 2: The Bland-Altman plot showing inter-session reproducibility (session 1 - session 2 ) in anterior chamber depth measurements for Subject 3. The mean difference $(-0.06 \mathrm{~mm})$ is small.

The coefficient of reproducibility (CRP) (no units) ranged from $0.11 \mathrm{~mm}-0.30 \mathrm{~mm}$ for AL, $0.82 \mathrm{~mm}-1.28 \mathrm{~mm}$ for ACD, and $0.54 \mathrm{~mm}-1.84 \mathrm{~mm}$ for LT. The CCC and associated 95\% CI for each entity are shown in Table 3.

Probability (or $p$ ) values were obtained from the paired $t$-tests conducted on the first $\mathrm{v}$. second sessions of measurements. All $p$ values obtained were $>0.05$. A $p$ value $>0.05$ suggests acceptance of the null hypothesis, which states that there is no difference between the means of the measurements taken during the first and second sessions. 


\section{Discussion}

Reliability of data is important in all clinical assessments, especially when evaluating whether a treatment intervention has any influence on a disease or whether a disease process produces change in measurements. ${ }^{20}$ The importance of $\mathrm{AL}$, ACD and LT measurements is well known in many clinical situations, such as in acute or chronic primary angle-closure

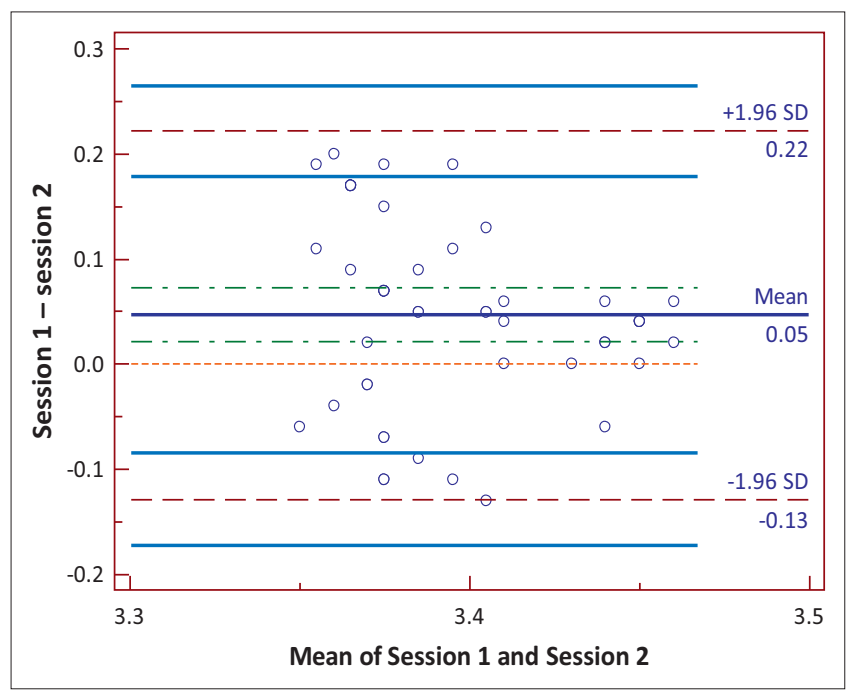

FIGURE 3: Bland-Altman plot for lens thickness measurements (in $\mathrm{mm}$ ) taken during sessions 1 and 2 for Subject 3. glaucoma, ${ }^{2}$ keratoconus, ${ }^{3,4}$ pseudophakia, ${ }^{21}$ and following ocular lens implantation. ${ }^{22,23}$ As instruments such as the Nidek US-500 Echoscan are now being used in clinical practice to measure these parameters, the results of the present study show that this instrument is a reliable measure of these ocular parameters in clinical settings.

\section{Intra-session repeatability}

As shown in Table 1, all the standard deviations for the data are close to zero $\mathrm{mm}$, suggesting that AL, ACD and LT measurements showed minimal variation within each of the 12 eyes. The COR values are small, indicating high repeatability ${ }^{24,25}$ of AL, ACD and LT measurements. Rudnicka et al. ${ }^{26}$ evaluated repeatability of the Allergan Humphrey model 820 ultrasonic biometer and showed that the 95\% confidence limits for repeatability lie between $-0.13 \mathrm{~mm}$ and $0.12 \mathrm{~mm}$ for AL, ACD and LT. These values compare well with those obtained in the current study. Shammas and Hoffner $^{27}$ evaluated the repeatability of measurements obtained with a new optical low-coherence reflectometer and reported excellent intra-session repeatability with a low COR for AL, ACD and LT measurements. Carl Zeiss Meditec ${ }^{28}$ also conducted a study to determine repeatability of their IOLMaster 500. Their results showed that that the s.d. for repeatability was $0.02 \mathrm{~mm}$ for $\mathrm{AL}$ and $0.03 \mathrm{~mm}$ for $\mathrm{ACD}$, which is consistent with those of the present study (see the

TABLE 2: Mean differences from Bland-Altman plots with 95\% lower and upper limits of agreement (LoA) alongside respective means for each subject.

\begin{tabular}{|c|c|c|c|c|c|c|}
\hline \multirow[t]{2}{*}{ Subject } & \multicolumn{2}{|c|}{ Axial length } & \multicolumn{2}{|c|}{ Anterior chamber depth } & \multicolumn{2}{|c|}{ Lens thickness } \\
\hline & Mean & $\begin{array}{l}95 \% \text { lower and upper } \\
\text { limits of agreement }\end{array}$ & Mean & $\begin{array}{l}95 \% \text { lower and upper } \\
\text { limits of agreement }\end{array}$ & Mean & $\begin{array}{l}95 \% \text { lower and upper } \\
\text { limits of agreement }\end{array}$ \\
\hline S1 & -0.04 & $-0.26 ; 0.19$ & -0.01 & $-0.22 ; 0.19$ & 0.04 & $-0.13 ; 0.20$ \\
\hline S3 & -0.02 & $-0.24 ; 0.19$ & -0.06 & $-0.28 ; 0.17$ & 0.05 & $-0.13 ; 0.22$ \\
\hline S4 & 0.05 & $-0.28 ; 0.38$ & -0.01 & $-0.15 ; 0.13$ & 0.01 & $-0.09 ; 0.11$ \\
\hline S5 & 0.01 & $-0.24 ; 0.16$ & -0.04 & $-0.22 ; 0.19$ & 0.02 & $-0.11 ; 0.18$ \\
\hline S7 & 0.06 & $-0.18 ; 0.17$ & -0.01 & $-0.20 ; 0.17$ & 0.04 & $-0.12 ; 0.19$ \\
\hline S8 & -0.01 & $-0.24 ; 0.20$ & 0.02 & $-0.15 ; 0.18$ & 0.01 & $-0.08 ; 0.13$ \\
\hline s9 & 0.04 & $-0.26 ; 0.30$ & 0.01 & $-0.13 ; 0.16$ & 0.00 & $-0.11 ; 0.12$ \\
\hline S10 & -0.01 & $-0.22 ; 0.17$ & -0.03 & $-0.23 ; 0.14$ & 0.04 & $-0.13 ; 0.18$ \\
\hline S11 & 0.03 & $-0.04 ; 0.16$ & -0.01 & $-0.20 ; 0.17$ & 0.05 & $-0.12 ; 0.24$ \\
\hline S12 & -0.03 & $-0.22 ; 0.18$ & 0.01 & $-0.15 ; 0.11$ & 0.00 & $-0.12 ; 0.10$ \\
\hline
\end{tabular}

TABLE 3: Concordance correlation coefficients with associated $95 \%$ confidence intervals alongside the Concordance correlation coefficients for each entity.

\begin{tabular}{|c|c|c|c|c|c|c|}
\hline \multirow[t]{2}{*}{ Subject } & \multicolumn{2}{|c|}{ Axial length } & \multicolumn{2}{|c|}{ Anterior chamber depth } & \multicolumn{2}{|c|}{ Lens thickness } \\
\hline & CCC & $95 \%$ confidence intervals & CCC & $95 \%$ confidence intervals & CCC & 95\% confidence intervals \\
\hline$\overline{\mathrm{S1}}$ & -0.38 & -0.26 to -0.16 & 0.12 & -0.15 to 0.38 & 0.14 & -0.03 to 0.31 \\
\hline S2 & -0.00 & -0.11 to 0.10 & -0.31 & -0.53 to -0.05 & -0.50 & -0.68 to -0.27 \\
\hline S3 & -0.14 & -0.31 to 0.04 & -0.11 & -0.27 to 0.04 & -0.22 & -0.43 to 0.00 \\
\hline S4 & -0.10 & -0.23 to 0.02 & 0.00 & -0.26 to 0.26 & -0.00 & -0.03 to 0.02 \\
\hline S5 & -0.40 & -0.52 to -0.12 & 0.16 & -0.12 to 0.30 & 0.12 & -0.03 to 0.26 \\
\hline S6 & -0.02 & -0.10 to 0.11 & -0.27 & -0.49 to -0.01 & -0.53 & -0.65 to -0.22 \\
\hline S7 & -0.11 & -0.30 to 0.02 & -0.12 & -0.22 to 0.01 & -0.18 & -0.38 to 0.02 \\
\hline S8 & -0.11 & -0.21 to 0.01 & 0.00 & -0.22 to 0.23 & -0.01 & -0.01 to 0.02 \\
\hline S9 & -0.33 & -0.44 to -0.11 & 0.13 & -0.11 to 0.36 & 0.11 & -0.01 to 0.22 \\
\hline S10 & -0.01 & -0.16 to 0.12 & -0.29 & -0.55 to -0.33 & -0.33 & -0.62 to -0.25 \\
\hline S11 & -0.12 & -0.43 to 0.06 & -0.14 & -0.25 to 0.06 & -0.21 & -0.40 to 0.02 \\
\hline S12 & -0.14 & -0.26 to 0.08 & 0.01 & -0.22 to 0.21 & -0.02 & -0.05 to 0.04 \\
\hline
\end{tabular}

CCC, Concordance correlation coefficients. 
s.d. for AL and ACD in Table 1). The Nidek US-500 Echoscan therefore compares favourably with the IOLMaster 500 and suggests that the Echoscan appears to be a reliable and valid clinical and research-oriented device.

\section{Inter-session reproducibility}

As with repeatability, the mean difference (MD) for each variable (Table 2$)$ is small $(-0.07 \mathrm{~mm}-0.05 \mathrm{~mm}$ for $\mathrm{AL}$, $-0.06 \mathrm{~mm}-0.04 \mathrm{~mm}$ for ACD, and $0.00 \mathrm{~mm}-0.07 \mathrm{~mm}$ for LT), suggesting that the differences between the two sets of measurements (sessions 1 and 2) for each variable for each subject are small. ${ }^{17}$ Also, paired $t$-tests indicate that there was no significant difference between the means of the 50 measurements taken during each of the two sessions. Therefore, there was excellent inter-session measurement reproducibility when the instrument was used to measure AL, ACD and LT 1 week apart. To visualise the MD and the 95\% LoA, data for one subject were presented graphically with the Bland-Altman plots, in which the difference of the values (session 1 and session 2) was plotted for each set of measurements (Figures 1, 2 and 3) against the means of the values (session 1 and session 2). The plots indicate that the MDs and the 95\% LoA are small, indicating good reproducibility of AL, ACD and LT measurements. This assertion is further supported by the CRP and CCC values (Table 3). The CRP gives an indication of how comparable measurements are when such measurements are obtained at different times, ${ }^{24}$ in this case 1 week apart. The smaller the CRP, the more confident one can be regarding the reproducibility of the data. ${ }^{17}$ The small CRP values obtained in this study therefore suggest that measurements conducted 1 week apart are reproducible.

The reproducibility values in this study compares well with those produced by previous studies ${ }^{13,27,28}$ using various instruments. For example, Shammas and Hoffner, ${ }^{27}$ using the Lenstar LS 900, reported excellent reproducibility for AL, ACD and LT values with Bland-Altman plots, showing the $95 \%$ LoA ranging from $-0.05 \mathrm{~mm}$ to $0.04 \mathrm{~mm}$ for AL, ACD $-0.22 \mathrm{~mm}-0.18 \mathrm{~mm}$, and LT $-0.21 \mathrm{~mm}-0.27 \mathrm{~mm}$. In addition, Carl Zeiss Meditec $^{28}$ reported good reproducibility of the IOLMaster for AL and ACD measurements (s.d. $=0.02 \mathrm{~mm}$ and $0.04 \mathrm{~mm}$ respectively).

\section{Conclusion}

The present study showed that the Nidek US-500 Echoscan provides repeatable and reproducible measurements of $\mathrm{AL}, \mathrm{ACD}$ and LT in healthy human eyes, albeit that the sample here was relatively small. These results support the findings of previous studies ${ }^{10,26}$ that ultrasonic devices are the reference standards for in vivo biometric axial measurements of the eye, such as AL, ACD and LT. It is recommended that, in future studies, the device be assessed on cyclopleged eyes as AL and ACD have been reported to vary during ocular accommodation. ${ }^{13}$ Also, as differences may be encountered when measuring eyes with ocular pathology such as glaucoma, and those which had undergone intraocular lens surgery, further studies on such subjects are required to more completely understand the reliability of the Nidek US-500 Echoscan when used to measure AL, ACD and LT.

\section{Acknowledgements}

This work is part of the $\mathrm{PhD}$ vision science project funded by the Medical Research Council (MRC). The author thanks Professor O.A. Oduntan for his kind review of the manuscript and the individuals who participated in this study.

\section{Competing interests}

The author declares that he has no financial or personal relationships which may have inappropriately influenced him in writing this article.

\section{References}

1. Lehman BM, Bernstsen DA, Bailey MD, Zadnik K. Validation of optical coherence tomography-based crystalline lens thickness measurements in children. Optom Vis Sci. 2009;86:181-187. http://dx.doi.org/10.1097/OPX.0b013e318198198d

2. Zarbin $M, C h u D$. Anterior chamber angle assessment techniques. Surv Ophthalmol. 2008;53:250-273. http://dx.doi.org/10.1016/j.survophthal.2007.10.012

3. Alleman N, Chamon W, Tanaka HM, Mori ES, Campos M, et al. Myopic angle-supported intraocular lenses: Two-year follow-up. Ophthalmology. 2000;107:1549-1554. http://dx.doi.org/10.1016/S0161-6420(00)00221-9

4. Emre S, Doganay S, Yologlu S. Evaluation of anterior segment parameters in keratoconic eyes measured with the Pentacam system. J Cataract Refract Surg. 2007;33:1708-1712. http://dx.doi.org/10.1016/j.jcrs.2007.06.020

5. Lackner B, Schmidinger G, Skorpik C. Validity and repeat ability of anterior chamber depth measurements with Pentacam and Orbscan. Optom Vis Sci. 2005;82:858-861. http://dx.doi.org/10.1097/01.opx.0000177804.53192.15

6. Wong TY, Foster PJ, Johnson GJ, Klein BE, Seah SK. The relationship between ocular dimensions and refraction with adult stature: the Tanjong Pagar Survey. Inv Ophthalmol Vis Sci. 2001;42:1237-1242.

7. Foster PJ. The epidemiology of primary angle closure and associated glaucomatous optic neuropathy. Semin Ophthalmol. 2002;17:50-58. http://dx.doi.org/10.1076/ soph.17.2.50.14718

8. Wong TY, Foster PJ, Seah SK, Chew PT. Rates of hospital admissions for primary angle closure glaucoma among Chinese, Malays, and Indians in Singapore. Br J Ophthalmol. 2000;84:990-992. http://dx.doi.org/10.1136/bjo.84.9.990

9. Mei L, Zhonghao W, Zhen M, Yimin Z, Xing L. Lens thickness and position of primary angle closure measured by anterior segment optical coherence tomography. J Clin Exp Ophthalmol. 2013;4:281. http://dx.doi.org/10.4172/2155-9570. 1000281

10. Chen YA, Hirnschall N, Findl O. Evaluation of 2 new optical biometry devices and comparison with the current gold standard biometer. J Cataract Refract Surg. 2011;37:513-517. http://dx.doi.org/10.1016/j.jcrs.2010.10.041

11. Nidek operator manual. Gamagori: Nidek Company, Ltd; April 2012.

12. Kurtz D, Manny R, Hussein M. Variability of the ocular component measurements in children using A-scan ultrasonography. Optom Vis Sci. 2004;81:35-33. http:// dx.doi.org/10.1097/00006324-200401000-00008

13. Shum PJ, Ko LS, Ng CL, Lin SL. A biometric study of ocular changes during accommodation. Am J Ophthalmol. 1993;115:76-81. http://dx.doi.org/10.1016/ S0002-9394(14)73528-7

14. Taylor BW, Kuyatt CE. Guidelines for evaluating and expressing the uncertainty of NIST measurement results. NIST technical note 1297. Washington, DC: United States Department of Commerce Technology Administration; 1994.

15. Moreno-Montanes J, Maldonado MJ, Garcia N, Mendiluce L, Garcia-Gomez PJ, Segui-Gomez M. Reproducibility and clinical relevance of the ocular response analyzer in nonoperated eyes: Corneal biomechanical and tonometric implications. Inv Ophthalmol Vis Sci. 2008;49:968-974. http://dx.doi.org/10.1167/iovs.070280

16. McGee HT, Fraunfelder FW. Toxicities of topical ophthalmic anesthetics. Expert Opin Drug Safety. 2007;6:637-640. http://dx.doi.org/10.1517/14740338.6.6.637

17. Bland JM, Altman DG. Agreement between methods of measurement with multiple observations per individual. J Biopharm Stat. 2007;17:571-582. http:// dx.doi.org/10.1080/10543400701329422

18. Bland M. An introduction to medical statistics. 3rd ed. Oxford: Oxford University Press, 2000; p. 272-274.

19. Medcalc [homepage on the Internet]. c2013 [cited 14 November 2013]. Available from: http://www.medcalc.org 
20. Dorel S, Couturier A, Hug F. Intra-session repeatability of lower limb muscles activation pattern during pedaling. J Electromyograph Kinesiol. 2008:18:857-865. http://dx.doi.org/10.1016/j.jelekin.2007.03.002

21. Nemeth G, Vajas A, Kolozsvari B, Berta A, Modis L. Anterior chamber depth measurements in phakic and pseudophakic eyes: pentacam versus ultrasound device. J Cataract Refract Surg. 2006;32:1331-1335. http://dx.doi.org/10.1016/j. jcrs.2006.02.057

22. Kucumen RB, Yenerel NM, Gorgun E, Kulacoglu DN, Dinc UA, Alimgil ML. Anterior segment optical coherence tomography measurement of anterior chamber depth and angle changes after phacoemulsification and intraocular lens implantation. J Cataract Refract Surg. 2008:34:1694-698. http://dx.doi.org/10.1016/j.jcrs.2008. 05.049

23. Yamaguchi T, Negishi K, Yuki K, Saiki M, Nishimura R, Kawaguchi N, et al. Alterations in the anterior chamber angle after implantation of iris-fixated phakic intraocular lenses. J Cataract Refract Surg. 2008;34:1300-1305. http://dx.doi.org/10.1016/j. jcrs.2008.04.033
24. Gillan WDH. On intra-session repeatability and inter-session reproducibility of ocular response analyzer (ORA) measurements. S Afr Optom. 2012;71:109-116.

25. Pueyo V, Polo V, Larrosa JM, Mayoral F, Ferreras A, Honrubia FM. Reproducibility of optic nerve head and retinal nerve fiber layer thickness measurements using optical coherence tomography. Archives of the Spanish Society of Ophthalmology. 2006;81:205-212.

26. Rudnicka AR, Steele CF, Crabb DP, Edgar DF. Repeatability, reproducibility and intersession variability of the Allergan Humphrey ultrasonic biometer. Acta Ophthalmol. 1992;70:327-334. http://dx.doi.org/10.1111/j.1755-3768.1992.tb08573.x

27. Shammas HJ, Hoffer KJ. Repeatability and reproducibility of biometry and keratometry measurements using a noncontact optical low-coherence reflectomete and keratometer. Am J Ophthalmol. 2012;153:55-61. http://dx.doi.org/ 10.1016/j.ajo.2011.06.012

28. Carl Zeiss Meditec, Inc. Clinical study: repeatability and reproducibility of 101LMaster 500 [homepage on the Internet]. c2010 [cited 19 December 2013]. Available from: http://www.accessdata.fda.gov/cdrh_docs/pdf10/K101182.pdf 